\title{
Areas of good practice and areas for improvement in work-integrated learning for radiography training in South Africa
}

\author{
J du Plessis, ${ }^{1} \mathrm{PhD}$; J Bezuidenhout, ${ }^{2} \mathrm{PhD}$ \\ ${ }^{1}$ Department of Clinical Sciences, Faculty of Health and Environmental Sciences, Central University of Technology, Bloemfontein, South Africa \\ ${ }^{2}$ Division Health Professions Education, Office of the Dean, Faculty of Health Sciences, University of the Free State, Bloemfontein, South Africa
}

Corresponding author: J du Plessis (duplesj@cut.ac.za)

\begin{abstract}
Background. Work-integrated learning (WIL) forms an essential part of many learning programmes to equip students with the required knowledge and a complete set of skills to be successful in the world of work. However, all aspects (teaching/learning, assessment and monitoring) of WIL have to be implemented appropriately to ensure quality learning for students to construct meaning from their learning.

Objective. To conduct an enquiry regarding the current practices for WIL in radiography training.

Methods. Using a questionnaire, a quantitative survey was conducted among selected university lecturers, workplace learning co-ordinators and finalyear radiography students at 7 South African universities.

Results. The results revealed the following areas of good practice: inclusion of activities to stimulate deep learning, development of soft skills, good management/co-ordination of WIL and existing good lines of communication. Improvement measures for identified areas include: use of different learning modes, increased use of electronic teaching media, involvement of workplace supervisors in the development of outcomes and learning material, quality supervision and adequate preparation of students prior to placement.

Conclusions. This study recommends the inclusion of WIL as part of the curriculum in healthcare programmes to assist students with the continuous development of new disciplinary knowledge and application of the acquired skills in the work environment.
\end{abstract}

Afr J Health Professions Educ 2019;11(3):101-106. https://doi.org/10.7196/AJHPE.2019.v11i3.1043

The changing nature of work and the capacity of educational institutions to prepare students for the changing work environment have been of concern to many governments. Consequently, linking on-campus learning with learning in industry has received increased attention. ${ }^{[1]}$ It is also applicable to healthcare education programmes, such as radiography, biomedical and clinical technology, nursing and other allied health professions, where conversion from analogue to digital requires student-centred curricula underpinned by clinical practice outcomes. ${ }^{[2]}$ To address this challenge, the Higher Education Qualifications Framework (HEQF $)^{[3]}$ in South Africa (SA) mandates all new qualifications to integrate theory and practice through incorporation of work-integrated learning (WIL) as a structured part of the curriculum. The WIL component of a programme should be properly structured, assessed and supervised, and should integrate university and workplace learning. ${ }^{[3]}$

In the WIL context, integration means that students take what they have learnt at university into the workplace. Conversely, what they have learnt in the workplace is taken into the next phase of learning when returning to university. ${ }^{[4]}$ Aside from workplace learning (WPL), WIL should preferably be facilitated using a variety of learning modes, e.g. work-directed theoretical learning (WDTL) - theoretical learning focused on what the student needs to know to be able to function sufficiently in the workplace; ${ }^{[5]}$ problem/scenario-based learning (PBL/SBL) - a method in which real-world problems are used to promote student learning; project-based learning and workplace learning $(\mathrm{PjBL})$ - an approach where students acquire deeper knowledge through active exploration of real-world challenges and problems, to stimulate the integration of concepts and higher order cognitive learning (deep learning) to construct understanding. ${ }^{[1,5-8]}$ Deep learners aim to understand the meaning behind the concept and interact with information by creating appropriate arguments and examples related to the topic. ${ }^{[9]}$ Ideally, the different learning modes should be used interchangeably in the delivery of WIL, while activities to accommodate these learning modes can occur in various environments (e.g. simulation laboratories, interactive discussion groups and forums, virtual and e-learning, the workplace). Exposing students to a combination of learning modes and environments has proved to promote deep learning and the development of soft skills, such as communication, confidence and assertiveness, time management, critical thinking, computer literacy, emotional intelligence, empathy and the ability to work in a team. ${ }^{[10]}$ Proficiency in these skills ensures that students are better equipped to function in the real world of work. Soft skills that promote employability are the qualities that an employer requires for success in the workplace. To deliver competent healthcare professionals, these skills should be developed as part of students' university training. ${ }^{[10]}$

Despite many positive aspects identified in the current delivery of WIL, the authors recognised some challenges regarding the curriculum design and facilitation, assessment and monitoring of WIL. These shortcomings in the training of healthcare students may produce graduates lacking the skills and competencies required for employment as professionals. Consequently, the following research question directed this study: 'What are the areas of good practice and areas for improvement in the current delivery of WIL in radiography training in SA?' In the absence of a structured programme for WIL in radiography training in SA, the aim of the study was to develop a 
WIL education and training programme for radiography by focusing on the requirements of the HEQF. ${ }^{[3]}$ The main objective was to conduct an enquiry with regard to the current practices for WIL in radiography training.

The developed programme was shared with the WIL co-ordinators at all participating SA universities for implementation in their programmes.

We report only on the areas of good practice and areas for improvement derived from a multifaceted enquiry with regard to the current status of WIL in radiography training at universities in SA..$^{[8,11-17]}$ Curriculum developers across all healthcare programmes can benefit from relevant information provided by this research to rectify possible shortcomings in the WIL component of their training.

\section{Methods}

\section{Research design and data collection}

Data for this cross-sectional, descriptive study were collected by means of a quantitative questionnaire survey. The questionnaire was developed by the researcher, who was guided by a questionnaire used for a benchmarking project on WIL conducted by the University of Tasmania (UTAS), Australia. ${ }^{[16]}$ With reference to curriculum design, teaching/learning, assessment and monitoring of WIL, the researcher developed the questions to specifically enquire about the delivery of WIL in radiography training at participating institutions. The questionnaire consisted mainly of 27 closed questions and allowed opportunity for open-ended comments. The same questionnaire was distributed to purposively selected lecturers, WIL co-ordinators and final-year students (who had been exposed to the thematic areas longer than other students) at all $7 \mathrm{SA}$ universities offering radiography training. Questions were rated from level 1 to 3, where level 1 indicated that effective strategies for the thematic areas were implemented successfully across the programme, and level 3 indicated that effective strategies for the thematic areas were not implemented successfully across the programme. Level 2 indicated existing strategies as useful, but with some limitations towards the sound implementation of these strategies. ${ }^{[16]}$ To augment the information, participants had the opportunity to provide comments.

\section{Sampling and statistical analysis}

The empirical phase of the study consisted of the administration of an electronic questionnaire to lecturers ( $n=14 / 32 ; 44 \%$ response rate) and WIL co-ordinators ( $n=22 / 44 ; 50 \%$ response rate), and a hard-copy questionnaire to final-year radiography students who had been exposed to WIL for a 3-year period ( $n=146 / 146 ; 100 \%$ response rate). The questionnaire was designed to obtain the views of all role players in the current training and delivery of WIL in radiography training at $7 \mathrm{SA}$ universities. Purposive sampling was used to select lecturers and supervisors, and random sampling was used for students by selecting every second student from the class list. ${ }^{[17]}$ The quantitative data were analysed by a statistician (e.g. frequencies, standard deviations, significance) and then organised, summarised and presented as descriptive statistics. ${ }^{[18]}$ Qualitative data from the open-ended comments were organised in themes that mirrored the concepts covered in the questionnaire.

\section{Ethical approval}

The Ethics Committee of the Faculty of Health Sciences, University of the Free State, Bloemfontein, SA, approved the protocol (ref. no. ECUFS NR 106/2012). Additional approval was granted by the heads of department at the 7 universities. To ensure anonymity, the questionnaires were coded using a number system. Validity was enhanced by the questionnaire being piloted on 4 lecturers, 4 supervisors and 4 final-year radiography students. Their recommendations were applied before distribution of the final questionnaire.

\section{Results \\ Areas of good practice}

When comparing the activities of lecturers to stimulate deep learning in the WIL environment, the results showed that lecturers' and students' feedback indicated similarity on only 3 actions (Fig. 1), including individual work (lecturers 62\%; students 54\%), group work (lecturers 61\%; students 64\%), and sharing responses (lecturers 63\%; students 67\%). For the other actions to stimulate deep learning, a difference in opinion between the lecturers and students was observed, from $12 \%$ (asking questions - lecturers $93 \%$; students $81 \%$ ) to $21 \%$ (issuing a challenge and allowing constructive critique - lecturers $82 \%$; students $61 \%$ ). There was also a difference between lecturers and students regarding the posing of a problem to stimulate deep learning (lecturers $82 \%$; students $76 \%$ ). There was a strong correlation between the lecturers' and students' results regarding the use of actions to stimulate deep learning $(r=0.664)$, indicating that most of the lecturers and students reported positively about the use of actions to stimulate deep learning in their programmes.

The development of soft skills was also identified as an area of good practice in the current delivery of WIL. Most lecturers (96\%) confirmed the development of soft skills in the facilitation and assessment of WIL at their respective institutions. Ninety-four percent of students indicated that soft skills were important for a healthcare professional to work effectively. Students reported the attainment of soft skills in their WIL programmes as follows: professional and ethical behaviour (88\%), communication (with patients, peers and managers) (91\%), critical thinking/problem-solving (86\%), integration of theoretical knowledge and practical skills (84\%), teamwork (84\%) and use of technology (85\%) (Fig. 2). Eighty-two percent of students confirmed that they were assessed on the attainment of soft skills in the WIL component of their programmes. When asked whether the employer created sufficient opportunities to develop skills and abilities in the workplace, $82 \%$ of students answered positively.

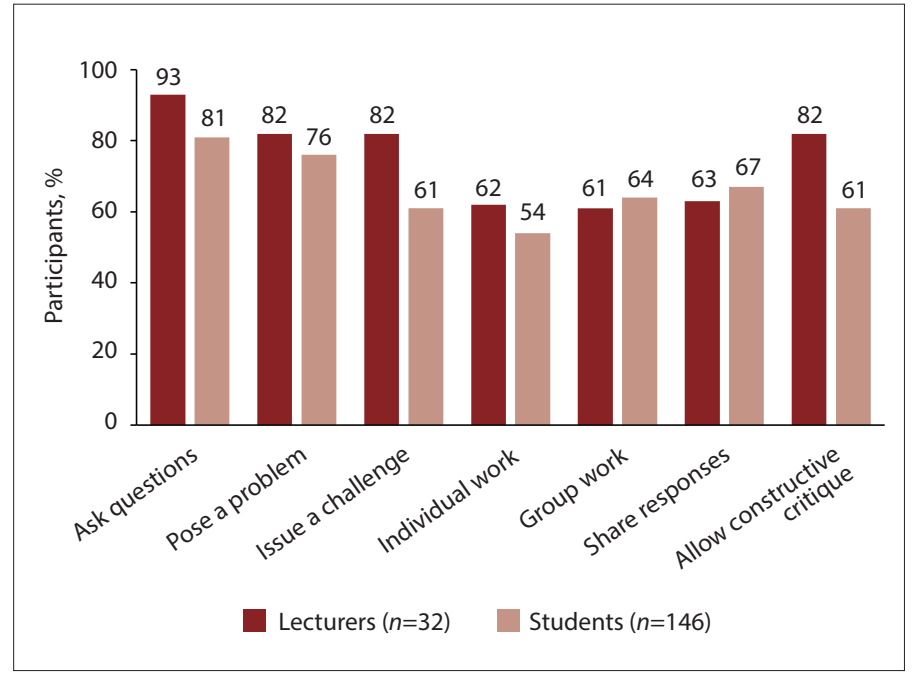

Fig. 1. Comparison of actions to stimulate active/deep learning. 


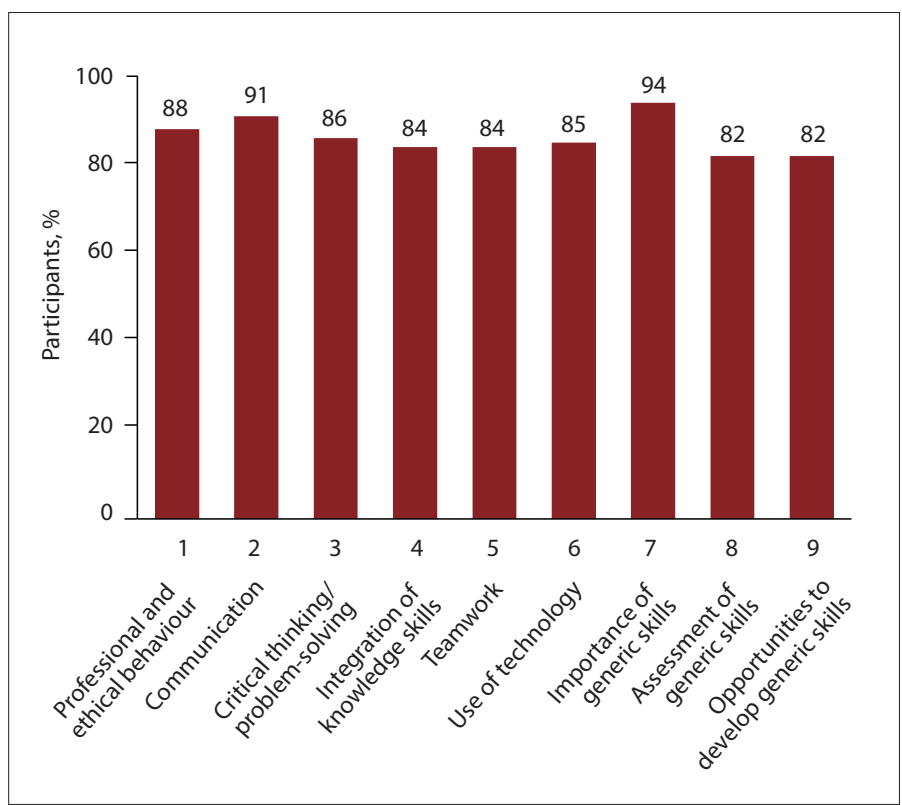

Fig. 2. Students' perceptions of the attainment of graduate attributes (soft skills) $(\mathrm{n}=146)$.

WPL supervisors were certain about who was responsible for the general management of WIL at their institutions (Fig. 3). They confirmed that the management and co-ordination of WIL are primarily controlled by the learning programme at the university $(55 \%)$ in collaboration with the WPL supervisor in clinical practice (55\%). The management and co-ordination of the WIL practices of students through the WIL central office at the 7 participating universities was $23 \%$, while the role of the faculty was $9 \%$.

There were adequately established lines of communication between all the universities and their clinical sites, although a variety of communication systems was used. The results in Fig. 4 show that email correspondence is the preferred line of communication between the co-ordinator/s at the university and the WPL supervisors at the clinical institutions (86\%). Advisory committee meetings were indicated as the second most used mode of communication regarding WIL-related and WPL-related matters (77\%), followed by standing committee meetings (41\%). Some universities indicated WIL committee meetings as the line of communication between the involved parties (23\%). Another 23\% indicated that other avenues were followed for communication between the different parties.

\section{Areas for improvement}

Certain areas for improvement were identified in the current application of WIL at participating universities, including the use of different learning modes for the facilitation of WIL. As shown in Fig. 5, WPL is the preferred learning mode of all lecturers in the participating programmes (100\%). WDTL was used by $71 \%$ of the lecturers. Learning modes such as PBL/ SBL, which are perfectly suitable for teaching in the WIL environment, were indicated as being used by $50 \%$ and $57 \%$, respectively. Only $43 \%$ of lecturers indicated the use of PjBL to facilitate the learning process in WIL.

An area showing a huge discrepancy in the responses of lecturers and students was the use of different types of electronic teaching media (Fig. 6) to facilitate learning when using the different learning modes of WIL. According to participating lecturers, PowerPoint was the medium mostly

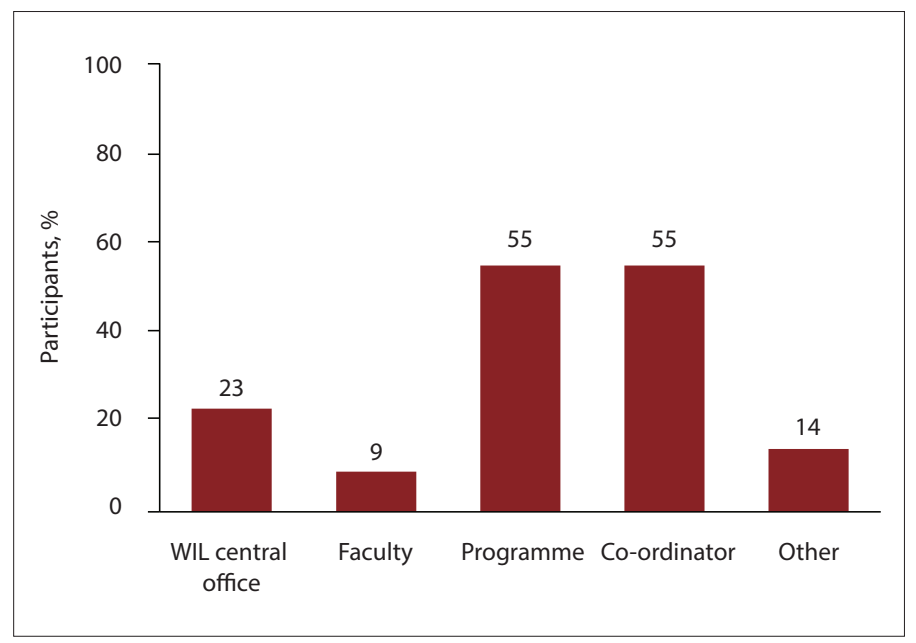

Fig. 3. Responsible entity $(\mathrm{n}=44)$. (WIL = work-integrated learning. $)$

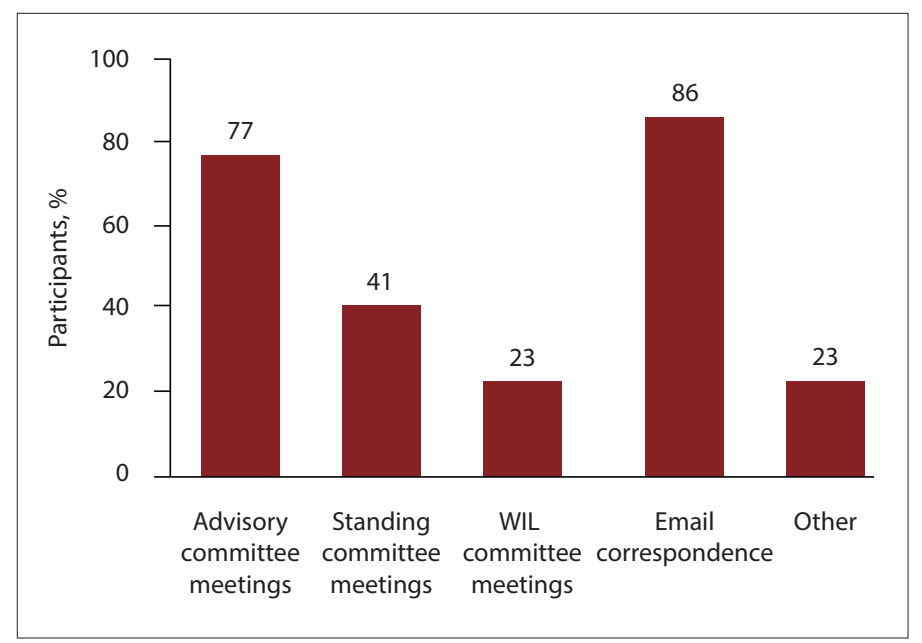

Fig. 4. Lines of communication $(\mathrm{n}=44)$. (WIL = work-integrated learning. $)$

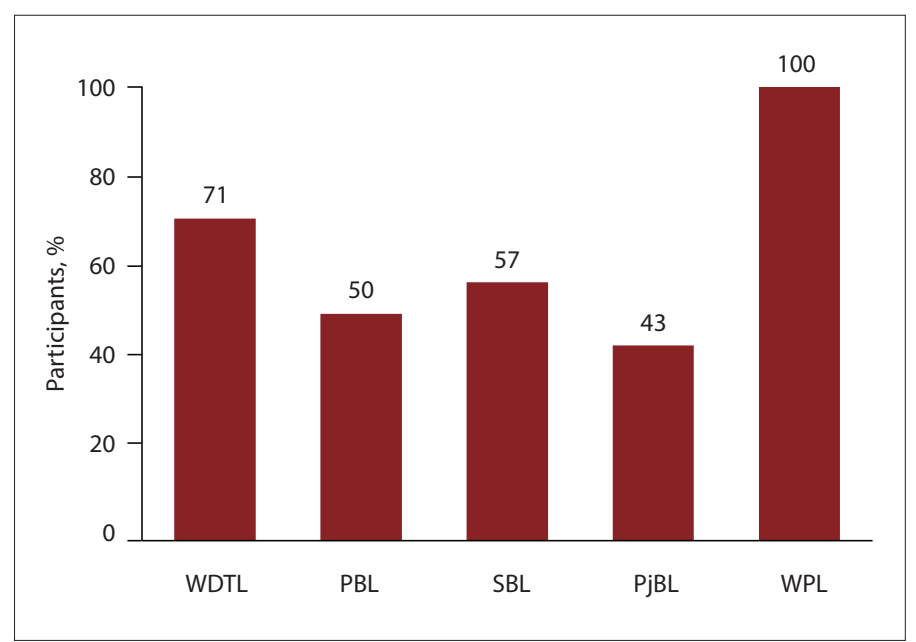

Fig. 5. Types of curricular modalities/learning modes used at participating institutions $(\mathrm{n}=32) .(W D T L=$ work-directed theoretical learning; $P B L=$ problem-based learning; $S B L=$ scenario-based learning; $P j B L=$ project-based learning; $W P L=$ workplace learning.) 
used when teaching WIL (100\%), followed by video (74\%), the internet and Blackboard (67\%), and Skype (56\%). The correlation between responses from students compared with those of lecturers was observed only for the use of PowerPoint (students 94\%; lecturers 100\%). Students indicated the use of video in teaching of WIL (45\%), as well as the internet (46\%), Blackboard (52\%) and Skype (34\%).

Other areas of concern included the involvement of WPL supervisors in the development of learning outcomes and learning material for the WIL component, as $50 \%$ of the WPL supervisors were positive regarding involvement, $27 \%$ indicated no involvement and $23 \%$ indicted some involvement (Fig. 7). The visitation of students by lecturers while placed for WPL seems to be a considerable challenge across all participating learning programmes. It was worrisome that $32 \%$ of the participating WPL

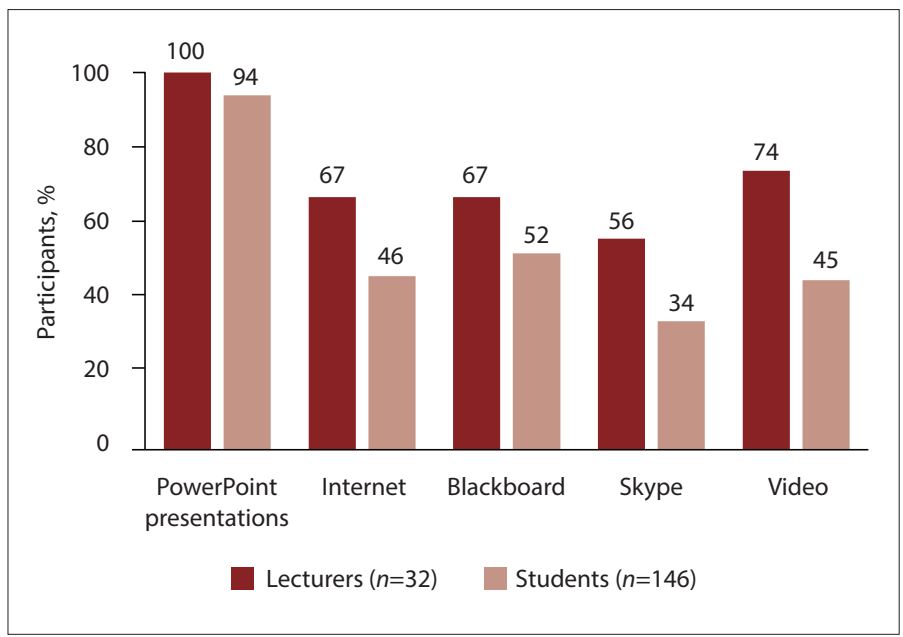

Fig. 6. Comparison of electronic teaching media used for work-integrated learning.

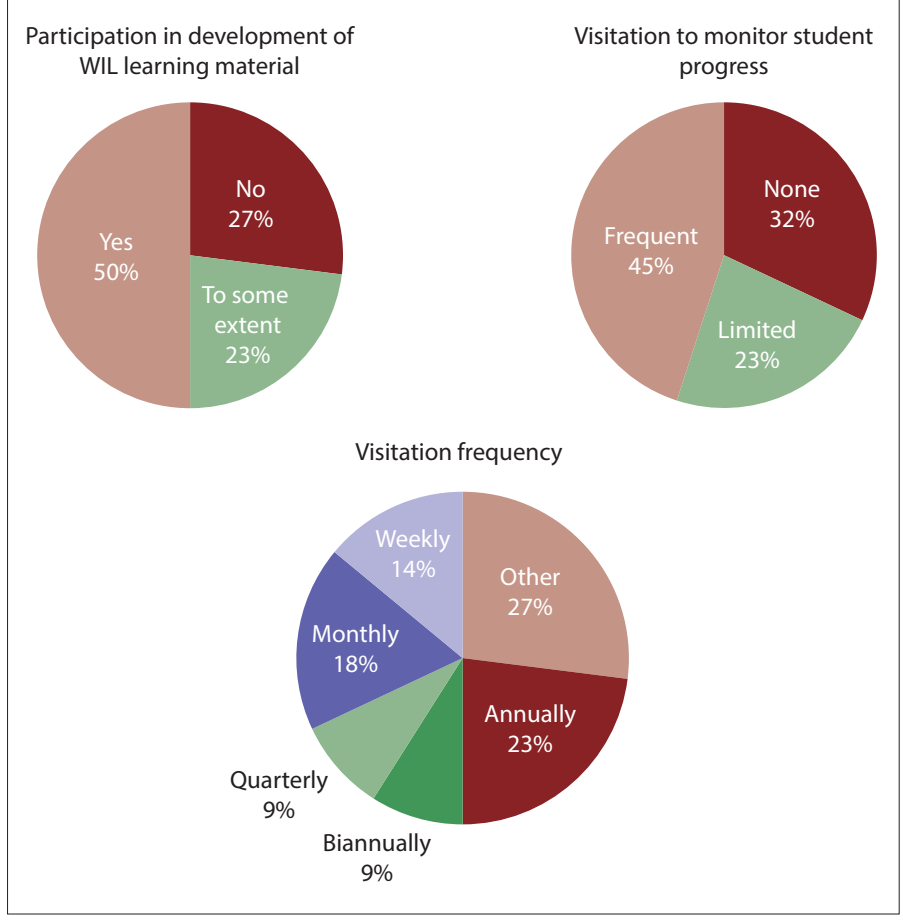

Fig. 7. Involvement and visitation. $($ WIL $=$ work-integrated learning. $)$ supervisors indicated that the WPL students were never visited by university lecturers (Fig. 7). Only 45\% of the WPL supervisors indicated frequent visits, while the remaining $23 \%$ reported limited visits. The frequency of visitation only once a year by a university lecturer/WIL co-ordinator was indicated by $23 \%$ of students. The frequencies of biannual and quarterly visits were both rated at $9 \%$, while monthly and weekly visits were rated at $18 \%$ and $14 \%$, respectively (Fig. 7 ).

The lack of training of supervisors and preparation of students prior to placement for WPL in clinical practice were regarded as a concern regarding the success of WIL. Only $41 \%$ of the WPL supervisors indicated that they had received appropriate training from their institutions for their supervisory role. However, a substantial number of WPL supervisors indicated some training (32\%) and no training (27\%) (Fig. 8). Related to the preparation of students before placement for WPL in clinical practice (Fig. 8), the supervisors indicated in favour of such pre-placement training (76\%). The remaining $26 \%$ indicated no pre-placement training programme (5\%) and limited pre-preparation training (19\%).

\section{Discussion}

Alignment of the outcomes with the level descriptors and exit-level outcomes for a qualification, as proposed by the South African Qualifications Authority (SAQA), ${ }^{[19]}$ is imperative for successful teaching and learning in any programme Therefore, the alignment of the learning outcomes for WIL with teaching/learning activities and assessment strategies is essential to the quality of learning. Lecturers and supervisors should embrace activities to stimulate deep learning, especially when working in the WIL components of their programmes. Deep learning is stimulated when working under the guidance of an experienced professional. Such assistance can stimulate critical thinking to help graduates/students link different concepts and thus develop a graduate who can function as an admirable professional in the workplace..$^{[20,21]}$

A key purpose of WIL is to provide graduates with a comprehensive set of soft skills preferred by potential employers, as indicated previously. ${ }^{[4]}$ Therefore, the incorporation of soft skills in the WIL curriculum of healthcare programmes should be encouraged. Similarly, the attainment of soft skills should be included in the assessment of WIL, whether assessed at the university or while the student is doing WPL. The WIL environment is ideal for assessing whether students have attained soft skills, and whether they are

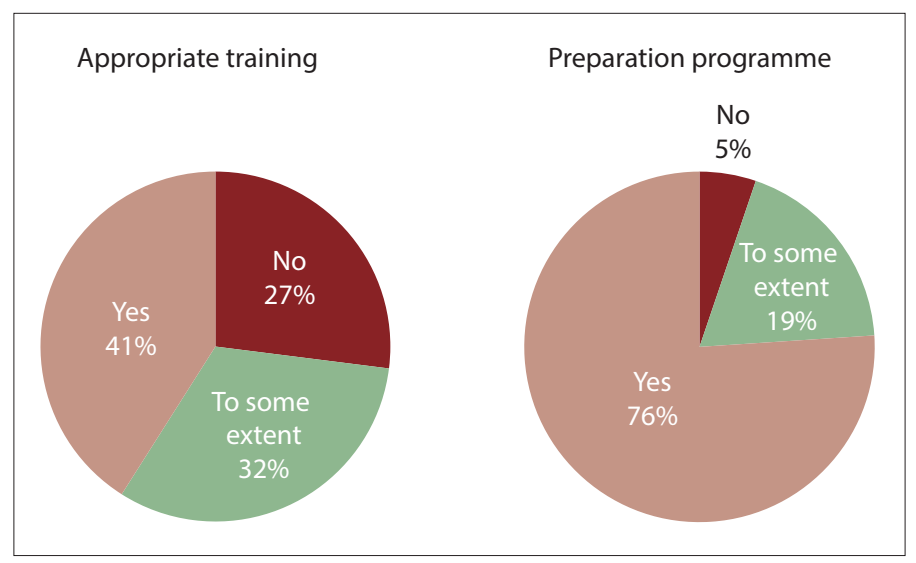

Fig. 8. Training of workplace learning supervisors and preparation of students before placement. 
able to apply them across a number of activities to ensure preparedness for clinical placement.

The management of WIL in a learning programme cannot be prescribed and may vary widely between programmes. However, the success of a WIL programme depends on the meaningful interaction of all the role players (students, universities and industry). ${ }^{[22]}$ It is therefore not important who the manager of the WIL component of the programme is, as long as collaborative action occurs between the WIL central office, learning programme, WIL co-ordinator/s, WPL supervisors in clinical practice and students. Similarly, good communication is an important aspect in ascertaining collaboration among role players, who need to communicate expectations about outcomes, assessment practices and monitoring. The avenues for communication between the different role players for WIL can also not be prescribed. It is important, however, that proper and timely communication occurs between the role players to ensure quality of learning in the WIL environment.

The results confirmed that WPL is still the preferred learning mode for training of healthcare professionals in the WIL environment. Also noteworthy is that a large percentage of the lecturers (71\%) used WDTL when teaching WIL. Conversely, PBL/SBL and PjBL were indicated across the spectrum of participating lecturers as being average (i.e. 43 - 57\%). For many health professions in SA, the popular use of WPL can be explained by these professions having had a professional body which, in the past, had prescribed a certain number of hours that students had to be placed in clinical practice as a prerequisite to obtain the qualification. This learning mode was compulsory. Nevertheless, the importance of PBL/SBL and $\mathrm{PjBL}$ in the WIL environment to stimulate the integration of theoretical knowledge with workplace skills development cannot be overemphasised. These learning modes are ideally suited to facilitate WIL, focusing on reallife problems and stimulating students to form the necessary links between what has been learnt in the classroom and what happens in the workplace. ${ }^{[23]}$ The different learning modes should be selected carefully to fit the purpose and level of students' learning. ${ }^{[7]}$

Facilitators must empower themselves to use electronic teaching media in an era where laptops, data projectors and internet connection have become part of everyday life. This is even more relevant in the healthcare professions, such as radiography, where online libraries and other electronic teaching tools are readily available. Students value lecturers' use of digital resources, which, alongside other forms of teaching support, steer them through the potentially overwhelming volume of work they have to master. ${ }^{[24]}$ Even though frequent visitation by a lecturer cannot be prescribed, it stimulates a culture of trust among all role players in the WIL environment. Frequent visitation by lecturers/WIL co-ordinators while doing WPL contributes to the success of the latter (personal communication with: (i) Mr Henri Jacobs, director, Work-integrated Learning and Skills Development, Central University of Technology, Bloemfontein, 12 October 2013; and (ii) Dr Marius Wessels, head, Cooperative Education Unit, University of Johannesburg, 11 March 2012). If frequent visitation is not possible, clear guidelines for monitoring and assessment must be available to WPL supervisors. It is even more important to train WPL supervisors correctly. The importance of supervision during WPL cannot be overemphasised, especially when policies and regulations regarding professional practice and human rights govern patient-related actions and activities. Students' WPL experience is an extension of the learning process. Therefore, supervisors should provide opportunities to bridge the two experiences and receive training for their important role of supervising students towards attaining a complicated set of skills. ${ }^{[25]}$

In most health professions programmes, it has become increasingly important that programme developers consider the development of soft skills during a preparation programme prior to placement of students in clinical practice. An increasingly demanding work environment requires that students have skills pertaining to professionalism, communication, the ability to work in groups, critical thinking and problem-solving. ${ }^{[2]}$ Therefore, at many universities, the inclusion of a core curriculum is now compulsory in an effort to address the acquisition of soft skills. We recommend that firstyear students be kept at university for some time before placement for WPL to develop these soft skills.

\section{Conclusions and recommendations}

We believe that the inclusion of WIL as part of the curriculum in many healthcare programmes will assist students to interchange continuously between disciplinary knowledge and the application of skills in the clinical environment. The delivery of quality WIL programmes is seen as an excellent tool to equip students with the employment qualities needed in a growing and increasingly demanding economy. At the conceptual level, it became clear that for education and training programmes to influence the quality of graduates for work in the health sector, new WIL curricula will have to be designed with a vision to align the teaching/learning, assessment and monitoring of the programme. The newly developed programme for WIL is currently being implemented and evaluated continuously to improve its delivery in radiography training in SA.

After comparing the results of the study with the challenges identified in the introduction, we recommend the following towards improvement of WIL practices in health programmes:

The teaching and learning of WIL in all health programmes should be planned and structured to incorporate different learning modes and environments such as skills and computer laboratories, not only the workplace.

The visitation of students by a university lecturer while they are engaged in WPL should receive urgent attention. Planning in conjunction with the available support structures at the university should be done to ensure that all students are visited as often as possible while they are engaged in WPL.

The developers of health professions programmes should give urgent attention to the training of WPL supervisors to ensure quality delivery of WIL. In this regard, we suggest the delivery of a structured course with continuing professional development units to encourage WPL supervisors to empower themselves for supervision and mentoring of students in clinical practice.

\section{Study limitations}

The main limitation of the study was that the student sample was limited to final-year radiography students; therefore, the perceptions of students regarding current WIL practices in the first and second years of study were excluded.

Declaration. The article is based on research conducted by JdP in partial fulfilment of her $\mathrm{PhD}$ thesis in Health Professions Education.

Acknowledgements. Dr Daleen Struwig, medical writer and editor, Faculty of Health Sciences, University of the Free State, Bloemfontein, for technical and editorial preparation of the manuscript. 
Author contributions. JdP: identified the research topic, conceptualised the study design, formulated the research aims and objectives, performed the collection and interpretation of the data and drafted the initial version of the article; JB: supervised the study and assisted with writing of the article; both authors approved the final version of the article.

\section{Funding. None.}

Conflicts of interest. None.

1. Wingrove D, Turner M. Where there is a WIL there is a way: Using a critical reflective approach to enhance work readiness. Asia Pac J Coop Educ 2015;16(3):211-222.

2. Engel-Hills PC An integrated approach to curriculum. S Afr Radiographer 2005:43(2):24-27.

3. Council on Higher Education. Work-integrated Learning: Good Practice Guide. Pretoria: CHE, 2011

4. Coll RK, Eames C, Paku L, et al. An exploration of the pedagogies employed to integrate knowledge in workintegrated learning in New Zealand higher education institutions. https://researchcommons.waikato.ac.nz handle/10289/5554 (accessed 6 August 2019).

5. Du Plessis JGE. A work-integrated learning education and training programme for radiography in South Africa. $\mathrm{PhD}$ thesis. Bloemfontein: University of the Free State, 2015. http://scholar.ufs.ac.za:8080/xmlui/bitstream/ handle/11660/1064/DuPlessisJGE.pdf?sequence= 1 (accessed 6 August 2019).

6. Petersen S. Principles of Curriculum Reform. University of the Free State: Division Health Sciences Education, 2013. 7. Howard P, Jorgensen D. Project-based learning and professional practice: Enhancing cooperative education. J Coop Educ 2006;40(2):1-11

8. Martin A, Hughes H. How to Make the Most of Work-integrated Learning: A Guide for Students, Lecturers and Supervisors. Albany, New Zealand: Massey University Press, 2009.

9. Lublin J. Deep, Surface and Strategic Approaches to Learning. Belfield: Centre for Teaching and Learning, University College Dublin, 2003.

10. Bowden T, Drysdale M. Work-integrated Learning in the 21st Century: Global Perspective on the Future. Bingley UK: Emerald Publishing, 2009.

11. Choy S, Delahaye B. Partnerships between universities and workplaces: Some challenges for work-integrated learning. Stud Contin Educ 2011;33(2):157-172. https:///doi.org/10.1080/0158037X.2010.546079

12. McLennan B, Keating S. Work-integrated learning (WIL) in Australian Universities: The challenges of mainstreaming WIL. ALTC NAGCAS National Symposium 19 June 2008, Melbourne, Australia. http://citeseerx.ist. psu.edu/viewdoc/download?doi=10.1.1.530.4443\&rep=rep 1\&type=pdf (accessed 7 June 2018).
13. Copper L Orrell L Bowden M. Work-integrated Learning. A Guide to Effective Practice London: Routledge, 2012 14. Govender CM, Qit M. Work-integrated learning benefits for student career prospects - mixed mode analysis. S Af J High Educ 2017;31(5):49-64. https://doi.org/10.20853/31-5-609

15. Lewis M, Hotlzhausen N, Taylor S. The dilemma of work-integrated learning (WIL) in South African highe education - the case of town and regional planning at the University of Johannesburg. http://journals.ufs.ac.za index.php/trp/article/view/428 (accessed 6 August 2019).

16. University of Tasmania (UTAS), Faculty of Business. Work-integrated learning benchmarking project. http://acen edu.au/docs/UTAS-WIL-Benchmarking-Project-Synopsis-Questionnaire.pdf (accessed 4 December 2017).

17. Bowling A. Research Methods in Health: Investigating Health and Health Services. 2nd ed. London: Open University Press, 2002.

18. Yan F, Robert M, Li Y. Statistical methods and common problems in medical or biomedical science research. Int Physiol Pathophysiol Pharmacol 2017;9(5):157-163.

19. South African Qualifications Authority. Registered Qualifications. Pretoria: SAQA, 2013.

20. Stirling A, Banwell J, MacPherson E, Heron A. A practical guide for work-integrated learning effective practices to enhance the educational quality of structured work experiences offered through colleges and universities. Highe Education Quality Control of Ontario. 2016. https://www.vu.edu.au/sites/default/files/CCLT/pdfs/heqco-practicelguide-wil.pdf (accessed 7 June 2018)

21. Atherton IS. Learning and teaching: Deep and surface learning. https://www.researchgate.net/ publication/246664388_Learning_and_Teaching_Deep_and_Surface_Learning (accessed 4 December 2017).

22. Forbes BE. Assessment strategies for work-integrated learning at higher education institutions. 2004. cctprojects. Forbes BE. Assessment strategies for work-integrated learning at higher educatio
co.za/wbeproject/documents/WIL/forbes-paper.pdf (accessed 4 December 2017).

3. Gallagher SA. Problem-based learning: Where did it come from, what does it do, and where is it going? J Edu Gifted 1997;20(4):332-362. https://doi.org/10.1177/016235329702000402

4. White D, Manton M. Open Educational Resources: The Value of Re-use in Higher Education. Oxford: University of Oxford, 2011 .

25. True M. Starting and maintaining a quality internship program. https://www2.virginia.edu/career/intern/ startinganinternship.PDF (accessed 4 December 2017).

26. Fleming J. Zinn C, Ferkins L. Bridging the gap: Competencies students should focus on during their cooperative experience to enhance employability. E-proceedings of the Asia Pacific Cooperative Education Conference 30 September - 3 October 2008, Sydney, Australia. acen.edu.au/resources/2008-conference-proceedings/ (accessed 4 December 2017).

Accepted 7 March 2019 